\title{
Specificity in Killing Pathogens Is Mediated by Distinct Repertoires of Human Neutrophil Peptides
}

\author{
Andreas Cederlund $^{\mathrm{a}}$ Birgitta Agerberth $^{\mathrm{a}}$ Peter Bergman ${ }^{\mathrm{b}, \mathrm{c}}$ \\ ${ }^{a}$ Department of Medical Biochemistry and Biophysics, Karolinska Institutet, ${ }^{b}$ Department of Laboratory Medicine, \\ Division of Clinical Microbiology, Karolinska Institutet, Karolinska University Hospital Huddinge and ' Department \\ of Medicine, Centre for Infectious Medicine (CIM), Karolinska University Hospital, Stockholm, Sweden
}

\section{Key Words}

Neutrophil · Polymorphonuclear leukocytes $\cdot$ Innate immunity $\cdot$ Mucosal immunity · Fungal infections • Bacterial infections $\cdot$ Moraxella catarrhalis $\cdot$ Staphylococcus aureus $\cdot$ Haemophilus influenzae $\cdot$ Candida albicans

\begin{abstract}
Neutrophil-derived antimicrobial peptides and proteins (AMPs) play an important role in the defense against microbes. Absence of defense is illustrated by neutropenic patients with frequent bacterial and fungal infections. However, the specificity of the antimicrobial effects has not been adequately described. We set out to determine the specific antimicrobial pattern of polypeptides in neutrophils (polymorphonuclear leukocytes, PMNs) against 4 potential human pathogens: Moraxella catarrhalis, Staphylococcus aureus, Haemophilus influenzae and Candida albicans. Protein extracts of human PMNs were separated using high-performance liquid chromatography and fractions were assayed for antimicrobial activity. Fractions displaying antimicrobial activity were separated on SDS-PAGE and characterized using MALDI-MS. Depletion experiments were utilized to determine the contribution of each AMP to the antimicrobial effect. Among the identified AMPs, $\alpha$-defensins 1-3, azurocidin, LL-37, lysozyme, calprotectin and lactotransferrin were
\end{abstract}

studied in detail. We found a divergent pattern of killing, that is, certain peptides and proteins exhibited selective activity against specific pathogens, while others displayed a broader antimicrobial activity. $\alpha$-Defensins, LL-37 and calprotectin were active against all species, while lactotransferrin exclusively inhibited growth of S. aureus. Conversely, azurocidin was active against all species except S. aureus. Our observations may shed light on bacterial resistance to AMPs and on the elimination of specific bacterial communities on mucosal surfaces.

Copyright $\odot 2010$ S. Karger AG, Basel

\section{Introduction}

Polymorphonuclear leukocytes (PMNs or neutrophils) are the first immune cells recruited to a site of infection, where they maintain host defense until adaptive immune cells are activated. Neutrophils contain a number of antimicrobial peptides and proteins (AMPs) that work in concert with the respiratory burst to achieve microbial killing [1]. The importance of neutrophils in host defense against pathogens is well established, in both mouse models and neutropenic patients. In mice, depletion of neutrophils leads to a marked reduction in clearance of bacteria from the lungs. Conversely, host defense

\section{KARGER}

Fax +4161306 1234 E-Mail karger@karger.ch www.karger.com
(C) 2010 S. Karger AG, Basel

$1662-811 X / 10 / 0026-0508 \$ 26.00 / 0$

Accessible online at:

www.karger.com/jin
Dr. Peter Bergman

Department of Laboratory Medicine, Division of Clinical Microbiology F68

Karolinska Institutet and Karolinska University Hospital, Huddinge

SE-14186 Stockholm (Sweden)

Tel. +4685858 0000, Fax +4685858 1305, E-Mail peter.bergman@ ki.se 
was restored when these mice were augmented with neutrophils [2]. Similarly, in humans it has been shown that neutropenia confers an increased risk of infections in general, but in particular in the upper respiratory tract (sinusitis, otitis media) and in the lung $[3,4]$. Furthermore, patients suffering from severe congenital neutropenia (Kostmann syndrome) are susceptible to bacterial infections of the respiratory system, ears and skin [5]. Despite treatments that restore neutrophil levels, these patients still suffer from recurrent infections, which has been suggested to be dependent on reduced levels of AMPs [6]. A selective lack of neutrophil-derived AMPs has also been demonstrated for the rare diseases Chediak-Higashi syndrome and specific granule deficiency, which are characterized by frequent and severe bacterial infections [7]. Combined, these observations suggest that both mice and humans are dependent on PMNs for clearance of infections and that their AMPs contribute to the defense against pathogenic microbes.

Neutrophil-derived AMPs can be divided into 3 general (and sometimes overlapping) groups based on their mechanism of antimicrobial action: cationic amphipathic peptides and proteins, chelating proteins and AMPs with enzymatic activity. The antimicrobial function of these peptides and proteins is generally well established, as well as their mechanism of bacterial killing [8-13]. However, previous studies of neutrophil-derived AMPs have mainly focused on the antimicrobial properties of a few selected AMPs or have utilized strict proteomic approaches without addressing antimicrobial activity. Furthermore, previous investigations with the aim of identifying novel AMPs have often been based on read-outs of antimicrobial activity against 'laboratory' bacterial strains, such as Bacillus megaterium (Bm11) or other modified bacterial strains. These strains are sensitive tools for detection of antimicrobial activity, but not always of clinical relevance. In conclusion, detailed information on which of the numerous neutrophil-derived antimicrobial peptides and proteins that is most important in the killing of human pathogens remains elusive. Therefore, we performed a screening experiment with the aim of elucidating the role of specific AMPs in the killing of 4 primary or opportunistic human pathogens: Staphylococcus aureus, Haemophilus influenzae, Moraxella catarrhalis and Candida albicans.

In this study, we identified 3 AMPs with a cationic character [ $\alpha$-defensins (HNP1-3), azurocidin and hCAP18/LL-37], 2 metal-chelating AMPs (calprotectin and lactotransferrin, LTF), 2 antimicrobial enzymes (lysozyme and cathepsin $\mathrm{G})$, as well as several histones (H1,
$\mathrm{H} 2 \mathrm{~B}, \mathrm{H} 3$ and $\mathrm{H} 4$ ), implicated in the antimicrobial activity against the tested pathogens. By depletion experiments with specific antibodies we could demonstrate that: (1) HNP1-3, calprotectin and LL-37 are important for the killing of all 4 pathogens analyzed, (2) LTF contributes to the killing of $S$. aureus but not to the killing of any of the other pathogens investigated and (3) azurocidin is important for the killing of H. influenzae, $M$. catarrhalis and C. albicans, but is not active against $S$. aureus.

This knowledge may be useful in the search for underlying mechanisms involved in clinical conditions of susceptibility to bacterial or fungal infections.

\section{Materials and Methods}

Isolation of PMNs

PMNs were isolated from buffy coats of healthy donors as previously described [14]. Briefly, buffy coats ( $<5$ h from venipuncture) provided by Karolinska Hospital Blood Bank, Stockholm, Sweden were subjected to dextran sedimentation and hypotonic lysing of erythrocytes. Thereafter, the sample was subjected to a density gradient centrifugation on Lymphoprep (Axis-Shield PoC AS, Oslo, Norway). The isolated PMNs were resuspended in PBS (without $\mathrm{Ca}^{2+}$ and $\mathrm{Mg}^{2+}$ ) to a concentration of $10 \times 10^{6}$ cells $/ \mathrm{ml}$ and assayed for purity and viability using Hemacolor (J.T. Baker, Utrecht, The Netherlands) and Trypan blue (Sigma-Aldrich, St. Louis, Mo., USA).

\section{Extraction of Neutrophil-Derived Polypeptides}

PMNs were extracted in $60 \%$ acetonitrile $(\mathrm{AcN})$ containing $1 \%$ trifluoroacetic acid (TFA) in $4^{\circ} \mathrm{C}$, subjected to centrifugation at $10,000 \mathrm{~g}$, and the resulting supernatant of the PMN extract was lyophilized.

\section{Degranulation of PMNs}

PMNs $\left(1 \times 10^{7}\right.$ cells) were stimulated with $100 \mathrm{nM}$ of formylmethionyl-leucyl-phenylalanine (fMLP; Sigma-Aldrich) in PBS (without $\mathrm{Ca}^{2+}$ and $\mathrm{Mg}^{2+}$ ) for 5 min followed by stimulation with $10 \mu \mathrm{M}$ of cytochalasin B (Sigma-Aldrich) for $5 \mathrm{~min}$. The resulting PMN supernatant was collected and lyophilized.

\section{Enrichment of Neutrophil-Derived Polypeptides}

Both the PMN supernatant and the PMN extract were reconstituted in $0.1 \%$ TFA and enriched for polypeptides on OASIS $3 c c$ HLB columns (Waters, Milford, Mass., USA), which had previously been activated with AcN and equilibrated in $0.1 \%$ TFA. Polypeptides were eluted with $80 \% \mathrm{AcN}$ in $0.1 \%$ TFA followed by lyophilization. The lyophilized materials were reconstituted in $0.1 \%$ TFA and the protein concentrations were determined using the Bradford protein assay [15]. The flow-through from the OASIS column did not contain any components with antimicrobial activity (data not shown). 


\section{Purification of Neutrophil-Derived Polypeptides of PMN}

Extract

The enriched PMN extract was separated by reversed-phase high-performance liquid chromatography (HPLC) utilizing a Vydac C8 column ( $4.6 \mathrm{~mm} \times 250 \mathrm{~mm}$; Grace, Columbia, Md., USA) over a gradient of $0-80 \%$ AcN in $0.1 \%$ TFA using ÄKTA purifier HPLC (GE Healthcare, Buckinghamshire, UK). The absorbance was monitored at $215 \mathrm{~nm}$. Fractions of $1 \mathrm{ml}$ were collected and lyophilized. The lyophilized fractions were reconstituted in 100 $\mu l$ water.

\section{Bacterial and Fungal Species}

Clinical isolates of the bacterial species $M$. catarrhalis and $H$. influenzae (nontypeable, nonencapsulated) were supplied by Dr. Eva-Lena Ericsson, Department of Clinical Microbiology, Karolinska University Hospital, Huddinge, Sweden. The isolates were verified using $16 \mathrm{~S}$ rRNA sequencing at the Department of Clinical Microbiology, Karolinska University Hospital, Solna, Sweden. The isolates of $S$. aureus strain Newman and the fungi C. albicans were obtained from American Type Culture Collection: ATCC 25904 and ATCC 14053.

\section{Inhibition Zone Assay}

The chromatographic fractions were assayed using a modified version of the radial diffusion assay [16] against the isolates of $S$. aureus strain Newman, $H$. influenzae, M. catarrhalis and the fungus C. albicans. Briefly, microbes were grown to an optical density of 0.6 in different growth media: $S$. aureus, Luria-Bertani broth; C. albicans, yeast and mold media; $M$. catarrhalis and $H$. influenzae, brain and heart infusion media with $2 \%$ Fildes supplement [containing pepsin-digested horse blood, hemin (X factor) and NAD (V factor)] (Oxoid, Cambridge, UK). Thereafter the microbes were diluted to $6 \times 10^{4} \mathrm{CFU} / \mathrm{ml}$ in $10 \%$ growth media containing 1\% agarose (A-6013; Sigma-Aldrich) with the exception of $H$. influenzae, which was assayed in $10 \%$ brain and heart infusion media supplemented with $1 \%$ Fildes, spread out into a 90-mm Petri dish (Sarstedt AG \& Co., Nümbrecht, Germany) and set to harden (final depth of agarose layer: $1 \mathrm{~mm}$ ). Holes of $3 \mathrm{~mm}$ in diameter were punched into the solidified agarose layer and 3 $\mu l$ of each chromatographic fraction was added to each hole. The plates were incubated at $35^{\circ} \mathrm{C}$ overnight.

\section{Gel Electrophoresis}

Chromatographic fractions were dissolved in lithium dodecyl sulfate sample buffer (Invitrogen, Carlsbad, Calif., USA), containing $50 \mathrm{~mm}$ dithiothreitol (Sigma-Aldrich). The samples were incubated at $70^{\circ} \mathrm{C}$ for $10 \mathrm{~min}$ and separated by SDS-PAGE, on $4-12 \%$ NuPage Bis-Tris gels (Invitrogen) at $200 \mathrm{~V}$ for $35 \mathrm{~min}$. Gels were stained with $0.1 \%$ Coomassie Brilliant Blue in $90 \%$ water, $8 \%$ methanol and $2 \%$ acetic acid (v/v/v) for $1 \mathrm{~h}$ and destained overnight in $90 \%$ water, $8 \%$ methanol and $2 \%$ acetic acid (v/v/v).

\section{Dot Blot Analysis}

For dot blot analysis $1 / 100$ of each chromatographic fraction was spotted onto a Hybond Super C nitrocellulose membrane (Amersham Biosciences, Buckinghamshire, UK). The membrane was treated with $5 \%$ fat-free milk in PBS for $1 \mathrm{~h}$ at room temperature (RT). After washing with $0.25 \%$ Tween in PBS the membrane was incubated with $0.6 \mu \mathrm{g} / \mathrm{ml}$ of primary antibody in $5 \%$ fat-free milk in PBS, $0.25 \%$ Tween 20 (Sigma-Aldrich) at RT for $1 \mathrm{~h}$. After an additional PBS washing step a secondary horseradish peroxidase-conjugated antibody was added and the membrane was incubated for $1 \mathrm{~h}$. Proteins and peptides were visualized on chemiluminescence film using the ECL plus Western blot detection system (GE Healthcare).

Antibodies: monoclonal antibody specific for LL-37 [17], S100A8 (goat polyclonal IgG, sc-8112; Santa Cruz, Santa Cruz, Calif., USA), HNP (goat polyclonal IgG, sc-22916; Santa Cruz), azurocidin (rabbit polyclonal IgG, sc-33129; Santa Cruz), lactotransferrin (mouse monoclonal, sc-52048; Santa Cruz), Lysozyme (rabbit polyclonal, A-0099; Dako, Stockholm, Sweden), Cathepsin G (rabbit polyclonal, ASHCG-AS; Molecular Innovations, Novi, Mich., USA).

\section{Western Blot Analysis}

For Western blot analysis, 1/25 of the chromatographic fractions were dissolved in lithium dodecyl sulfate sample buffer and separated as described above in the Gel Electrophoresis section. After the electrophoretic separation, proteins in the gels were blotted onto a polyvinylidene fluoride membrane (Invitrogen) at $30 \mathrm{~V}$ for $1 \mathrm{~h}$. Blocking and detection of polypeptides on the polyvinylidene fluoride membrane was performed as described in the Dot Blot Analysis section.

\section{Trypsin Digestion and Peptide Mass Fingerprinting}

Gel bands were manually excised and proteins were in-gel digested with trypsin using the MassPREP robotic protein handling system (Waters). The gel pieces were destained twice with $100 \mu \mathrm{l}$ $50 \mathrm{mM}$ ammonium bicarbonate (Ambic) in $50 \%$ (v/v) AcN at $40^{\circ} \mathrm{C}$ for $10 \mathrm{~min}$. Subsequently the polypeptides were reduced with 10 $\mathrm{mM}$ dithiothreitol in $100 \mathrm{~mm}$ Ambic for $30 \mathrm{~min}$, alkylated with 55 mM iodoacetamide in $100 \mathrm{~mm}$ Ambic for $20 \mathrm{~min}$, and dehydrated in AcN. To the sample solutions, 300 ng trypsin (Promega, Madison, Wisc., USA) in $50 \mathrm{~mm}$ Ambic was added and incubated for $5 \mathrm{~h}$ at $40^{\circ} \mathrm{C}$. Peptides were eluted from the gel pieces by using 30 $\mu \mathrm{l} 1 \%$ formic acid in $2 \% \mathrm{AcN}$, followed by extraction in $3 \times 15 \mu \mathrm{l}$ $50 \%$ AcN. Tryptic peptides were mixed 1:1 (v:v) with saturated $\alpha$-cyano-4-hydroxycinnamic acid (Bruker Daltonics, Billerica, Mass., USA), previously diluted 1:3 in 70\% AcN. The molecular weights of the fragments were determined using the VoyagerDETM PRO matrix-assisted laser desorption/ionization mass spectrometer (MALDI-MS; Applied Biosystems, Foster City, Calif., USA). The polypeptides were identified by database searches utilizing the MASCOT search engine with the UniProtKB/SwissProt Release 57.3 database.

\section{Depletion of the Activity of Individual AMPs in the PMN \\ Extract and Active Chromatographic Fractions}

After identifying proteins in the antimicrobially active chromatographic fractions using peptide mass fingerprinting (PMF), several fractions were grouped into clusters (I-VII) and pooled accordingly. To verify the contribution of specific AMPs to the total antimicrobial activity in a cluster, AMPs identified in the clusters were subjected to depletion of the antimicrobial activity using specific polyclonal or monoclonal antibodies directed against the individual AMPs identified by PMF. The pooled fractions were lyophilized and reconstituted in either specific antibody (final concentration $3 \mathrm{mg} / \mathrm{ml}$ ), sterile water or an unspecific control antibody. The control antibodies were chosen to match the specific anti-AMP antibodies: mouse monoclonal an- 
ti-rabbit IgG (Sigma R1008), rabbit polyclonal anti-tubulin (Sigma SAB3500023) and goat polyclonal anti- $\beta$-actin (Abcam; ab8229). These antibodies did not reduce any antimicrobial activity by themselves at the concentration of $3 \mathrm{mg} / \mathrm{ml}$ (fig. 4, 5a; data not shown). The mixtures were incubated at RT for $1 \mathrm{~h}$. The reduction in activity of fractions blocked with the specific or control antibody was assayed in the inhibition zone assay as described above. For depletion experiments, the PMN extract (25 $\mu \mathrm{g} / \mu \mathrm{l}$ ) was reconstituted in either PBS, control antibody (final concentration $3 \mathrm{mg} / \mathrm{ml}$ ) or an AMP-specific antibody (final concentration $3 \mathrm{mg} / \mathrm{ml}$ ) at RT for $1 \mathrm{~h}$, and the antimicrobial activity was assayed in the inhibition zone assay.

\section{Minimum Inhibitory Concentration}

HNP1-3 (AbD Serotech, Oxford, UK), recombinant human azurocidin (provided by Prof. Lennart Lindbom, Karolinska Institutet), calprotectin heterodimer (S100A8/A9; provided by Dr. Walter J. Chazin, Vanderbilt University, USA), LTF and human lysozyme (L-6394; Sigma-Aldrich) and LL-37 (Innovagen, Lund, Sweden) were analyzed in the inhibition zone assay for determination of the minimum inhibitory concentration (MIC) [18]. Histone sulfate from calf thymus containing $\mathrm{H} 1, \mathrm{H} 2 \mathrm{~A}, \mathrm{H} 2 \mathrm{~B}, \mathrm{H} 3$ and H4 (Fluka AG, Buchs, Switzerland) was utilized for MIC determination of histones. These bovine histones are highly homologous to human histones ( $\mathrm{H} 1$ : 95.4\% sequence identity, $\mathrm{H} 2 \mathrm{~A}$ : $100 \%$, H2B: 99.2\%, H3: 97\% and H4: 100\% identity). Briefly, 2-fold dilutions of each AMP in sterile water were analyzed in the inhibition zone assay and the diameters of the zones were corrected by subtraction of the hole diameter $(3 \mathrm{~mm})$. Linearity was observed when plotting the logarithm of the peptide concentration as a function of the corrected zone diameter. Using linear regression (least squares algorithm), the MIC was determined as the intercept of the linear regression with the $\mathrm{x}$-axis.

\section{Results}

\section{Extraction and Purification of Neutrophil-Derived AMPs}

To investigate the antimicrobial properties of neutrophil-derived peptides and proteins, PMNs pooled from 4 healthy blood donors were either extracted with $1 \%$ TFA in $60 \%$ AcN (PMN extract) or degranulated using fMLP and cytochalasin B, and the supernatant was collected (PMN supernatant). The PMN extract and the PMN supernatant were then enriched for polypeptides and their antimicrobial activities were compared. Both exhibited antimicrobial activity against 4 common human pathogens (S. aureus, $H$. influenzae, $M$. catarrhalis and C. albicans) when tested in an inhibition zone assay. The most sensitive bacterium was $M$. catarrhalis (zone diameter of $11 \mathrm{~mm}$ for the PMN extract and $9.5 \mathrm{~mm}$ for the PMN supernatant), whereas the most resistant pathogen was $H$. influenzae (zone diameter of $7 \mathrm{~mm}$ for the PMN extract and $6.5 \mathrm{~mm}$ for the PMN supernatant)

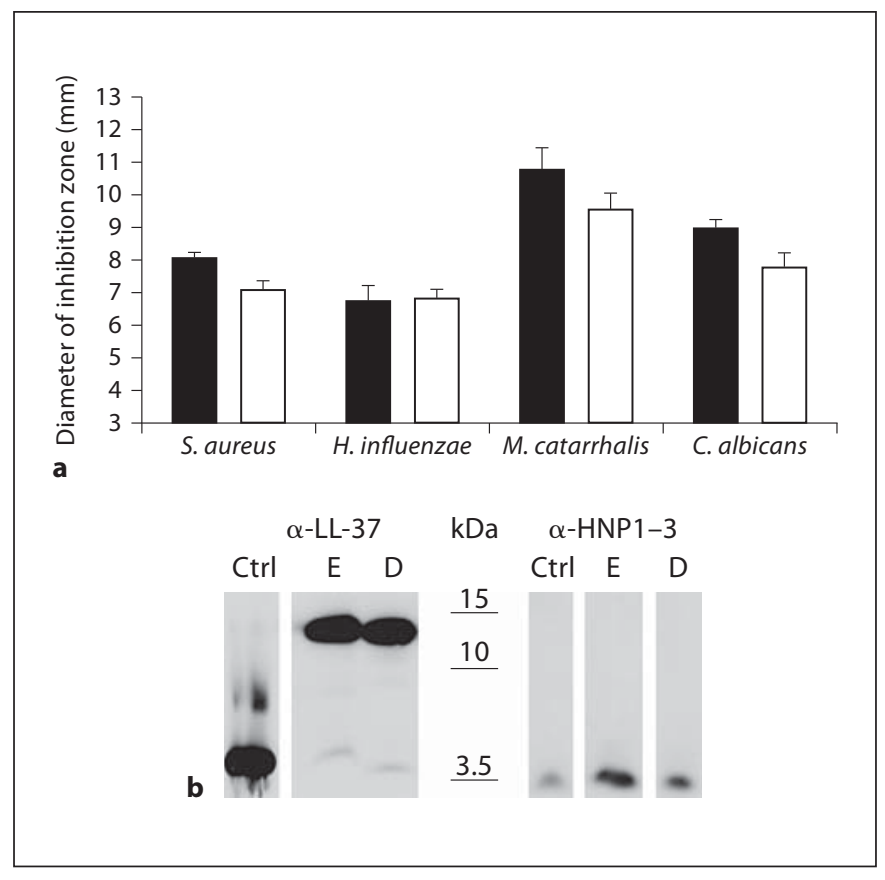

Fig. 1. a Antimicrobial activity of PMN extract and PMN supernatant. Inhibition zone assay of a PMN extract (extracted from $1 \times 10^{7}$ cells $\left./ \mathrm{ml}\right)$. The PMNs $\left(1 \times 10^{7}\right.$ cells $\left./ \mathrm{ml}\right)$ were extracted in $1 \%$ TFA in $60 \%$ overnight (black bars) or degranulated using fMLP and cytochalasin B (PMN supernatant, white bars). Both PMN extract and PMN supernatant were dissolved in $0.1 \%$ TFA to a concentration of $25 \mu \mathrm{g} / \mu \mathrm{l}$ and were assayed for antimicrobial activity against $S$. aureus, $H$. influenzae, $M$. catarrhalis and C. albicans. Two independent experiments were performed in triplicates. One representative experiment is shown $(n=3)$. b Presence of AMPs originating from primary and secondary granules in PMN extract and PMN supernatant. Ten micrograms of protein from $1 \times 10^{7} \mathrm{PMN}$ extract, PMNs extracted in either $1 \%$ TFA in $60 \%$ AcN overnight (lane E) or PMN supernatant, $1 \times$ $10^{7}$ PMNs degranulated using fMLP and cytochalasin B (lane D) was analyzed with Western blot using an antibody against LL-37 and HNP1-3. The monoclonal LL-37 antibody recognizes both the pro-form hCAP18 and the mature peptide LL-37. Positive controls were run in parallel (lane Ctrl). Two independent experiments were performed and 1 representative experiment is shown.

(For figure see next page.)

Fig. 2. a-e Antimicrobial activity in chromatographic fractions of PMN extract. a PMN extract (8 mg) was fractionated by a C8 reversed-phase column employing a gradient of $20-60 \% \mathrm{AcN}$ in $0.1 \%$ TFA. Fractions of $1 \mathrm{ml}$ were collected, lyophilized, reconstituted in $0.1 \%$ TFA and assayed in the inhibition zone assay. Fractions are grouped into subsets, or clusters denominated with Roman numerals I-VII. Black bars indicate antimicrobial activity in the form of diameters in an inhibition zone assay of fractions against S. aureus (b), H. influenzae (c), M. catarrhalis (d) and C. albicans (e). 


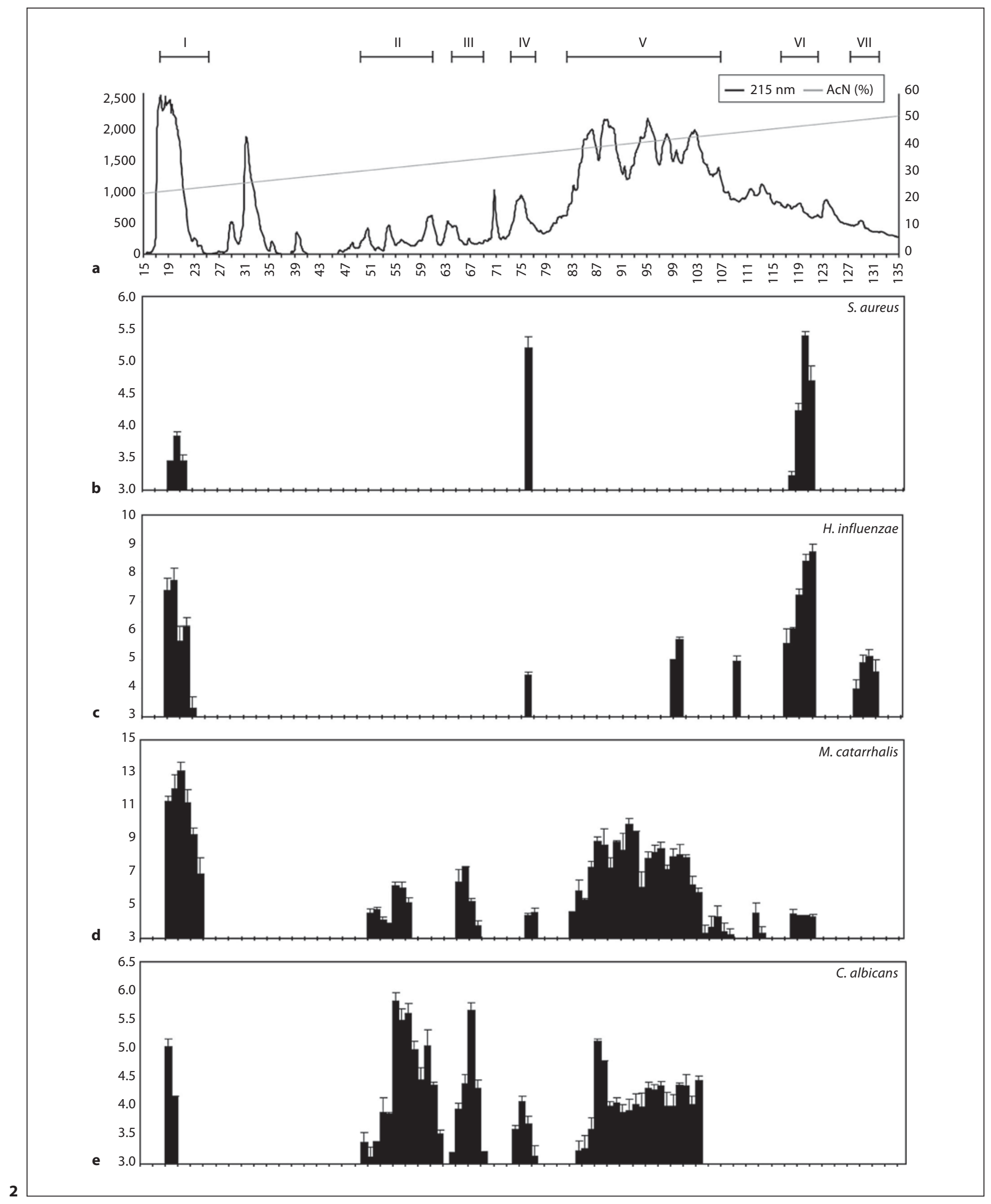




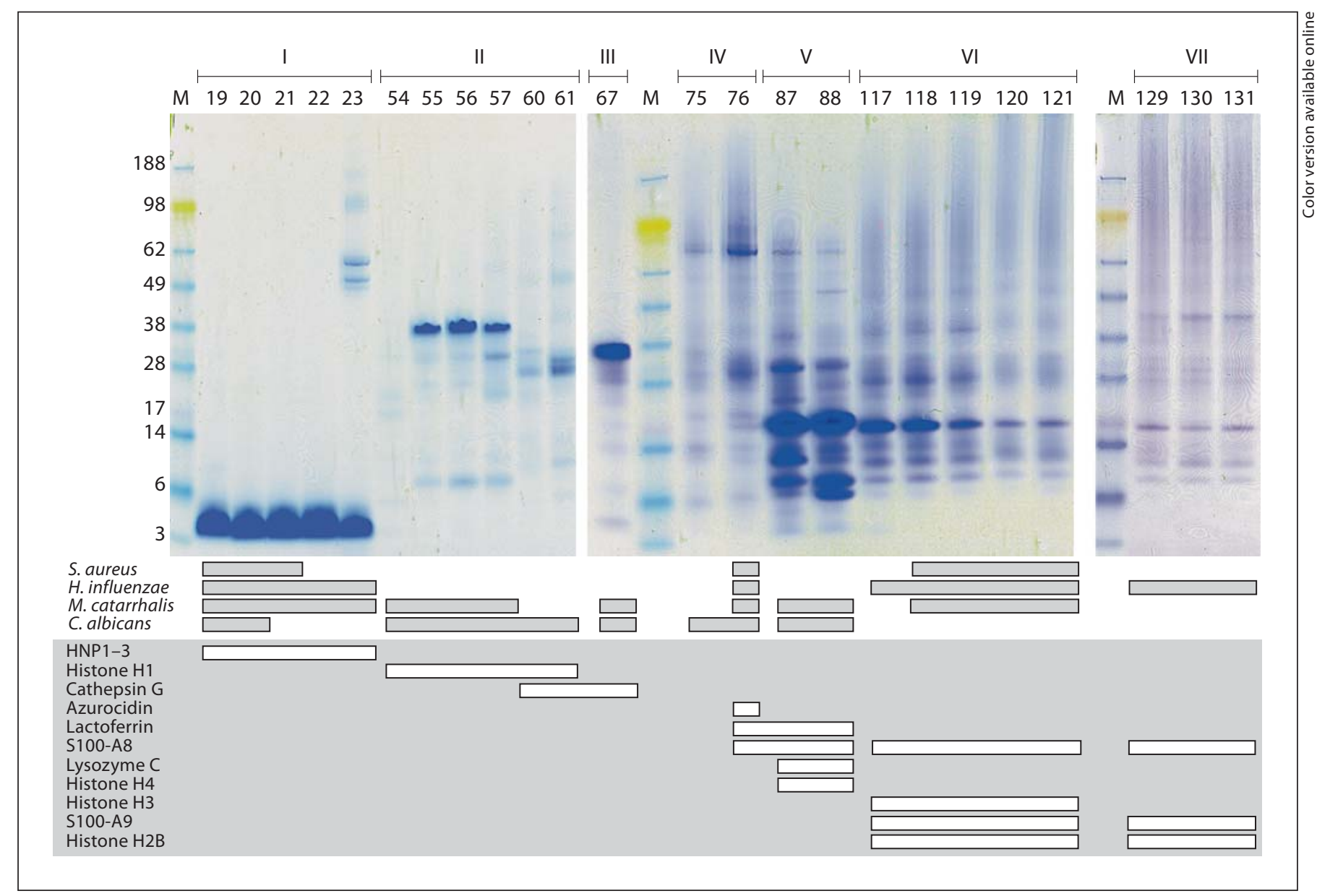

Fig. 3. Gel electrophoresis of chromatographic fractions displaying antimicrobial activity. Fractions with activity against $S$. $a u-$ reus, $H$. influenzae, $M$. catarrhalis or C. albicans were further separated by SDS-PAGE. Gels were stained with Coomassie Blue. Ro- man numerals (I-VII) represent the different clusters. Fractions displaying activity against individual microbial species (grey horizontal bars) and the identified AMPs (white horizontal bars) are indicated below the gel image. (fig. 1a). The AMP compositions in the PMN extract and supernatant were investigated utilizing Western blot analyses with antibodies directed against peptides of primary (HNP1-3 [8]) and secondary (LL-37 [19]) granules. The PMN extract and the PMN supernatant contained similar amounts of these AMPs (fig. 1b) and since the antimicrobial activities did not differ considerably between the PMN extract and supernatant (fig. 1a), we chose to use PMN extracts for further experiments. A further reason for using a whole-cell extract was that we wanted to include all cellular compartments of the neutrophil, including nuclear, cytoplasmic as well as granular peptides and proteins. We reasoned that this approach may be important since neutrophils are shortlived cells (approximately $24 \mathrm{~h}$ ) and have dual anti- bacterial functions, utilizing phagolysosomal as well as neutrophil extracellular trap (NET)-mediated bacterial killing. Thus, we aimed at investigating AMPs being involved in both of these processes.

\section{Identification of Antimicrobial Polypeptides}

In order to identify the individual components that contributed to the observed antimicrobial effect of the PMN extract, further isolation was performed by reversed-phase HPLC. The antimicrobial activity of the chromatographic fractions plotted in figure 2a-e segregated into a number of distinct clusters (I-VII). For further identification of AMPs, fractions from the different clusters were separated on SDS-PAGE. Excised protein bands were in-gel digested and analyzed using PMF. 
Table 1. Polypeptides identified in fractions with antimicrobial activity utilizing MALDI-MS

\begin{tabular}{lcrlrcll}
\hline Protein & Mr, Da & $\begin{array}{l}\text { Mascot } \\
\text { score }\end{array}$ & $\begin{array}{l}\text { Coverage } \\
\%\end{array}$ & $\begin{array}{l}\text { Peptides } \\
\text { detected }\end{array}$ & Range & Detected in fraction \\
\hline HNP1-3 & 10536 & 65 & 26 & 5 & $70-94$ & $19-23$ & Cluster \\
Platelet factor 4 & 11123 & 70 & 43 & 5 & $46-93$ & $54-57$ & I \\
High-mobility group protein B1 & 25049 & 79 & 37 & 9 & $13-163$ & $54-57$ & II \\
Histone H1 & 22566 & 162 & 41 & 14 & $2-198$ & $55-62$ & II \\
Cathepsin G & 29151 & 140 & 50 & 13 & $49-239$ & $60-61,67$ & II, III \\
Azurocidin & 27325 & 62 & 39 & 6 & $37-231$ & 76 & IV \\
Cofilin-1 & 18719 & 83 & 57 & 9 & $14-146$ & 76 & IV \\
Lysozyme C & 16982 & 78 & 33 & 7 & $32-131$ & $76-92$ & IV, V \\
Lactoferrin & 80014 & 384 & 53 & 35 & $38-709$ & $76,86-89$ & V V \\
Histone H4 & 11360 & 57 & 39 & 5 & $25-78$ & $84-103$ & V \\
Tropomyosin a-4 & 28619 & 139 & 32 & 14 & $13-208$ & $87-88$ & V \\
hCAP-18 & 19517 & 66 & 43 & 9 & $3-162$ & $98-103$ & V, VI, VII \\
S100-A8 & 10885 & 115 & 64 & 8 & $1-93$ & $76,86-92,117-122,129-131$ \\
Hemoglobin subunit $\beta$ & 16102 & 78 & 48 & 6 & $32-145$ & 118 & VI \\
Histone H3 & 15509 & 62 & 27 & 6 & $42-129$ & $117-121$ & VI \\
Histone H2B & 13944 & 86 & 60 & 10 & $36-117$ & $117-121,129-131$ \\
S100-A9 & 13291 & 127 & 92 & 10 & $5-114$ & $117-122,129-131$ & VI, VII \\
\hline
\end{tabular}

Identification of polypeptides detected in fractions was performed using MALDI-MS. Gel bands were excised from the SDS-PAGE (fig. 3) in-gel digested with trypsin and identified using PMF.

Two clusters exhibited activity against all 4 pathogens (cluster I and cluster IV, fig. 2b-e). The first (cluster I, fraction 19-21) eluted at $25-30 \% \mathrm{AcN}$ and represents peptides/proteins with moderate hydrophobicity. SDS PAGE revealed a single band of $4 \mathrm{kDa}$ (fig. 3; table 1), which was shown to contain HNP1-3 by PMF and dot blot analysis (data not shown). The other cluster with activity against all test strains eluted at $38 \% \mathrm{AcN}$ (cluster IV, fraction 74-77) and the fraction with the highest activity of this cluster (fraction 76), contained S100A8 $(6.5 \mathrm{kDa})$, lysozyme C $(14 \mathrm{kDa})$, cofilin-1 $(18 \mathrm{kDa})$, azurocidin $(25 \mathrm{kDa})$ and LTF $(80 \mathrm{kDa})$ by PMF (fig. 3; table 1).

Three clusters were exclusively active against C. albicans and M. catarrhalis. They eluted at $30-35 \%$ AcN (cluster II, fractions 49-61), 35-38\% AcN (cluster III, fractions 63-68) and 40-45\% AcN (cluster V, fractions 82-106 (fig. 2d, e). Fractions 54-57 of cluster II contained 3 major polypeptides of approximately 7, 25 and $30 \mathrm{kDa}$. These were identified with PMF to be platelet factor 4 (9 $\mathrm{kDa})$, high-mobility group protein $\mathrm{B} 1(26 \mathrm{kDa})$ and histone $\mathrm{H} 1(35 \mathrm{kDa})$. Fractions 60 and 61 of cluster II contained both cathepsin $\mathrm{G}(28 \mathrm{kDa})$ and histone $\mathrm{H} 1$ (30 $\mathrm{kDa}$ ) as determined by PMF (fig. 3; table 1).
In fraction 67 of cluster III, cathepsin G (30 kDa) could be identified, utilizing PMF (fig. 3; table 1) and dot blot analysis (data not shown).

Fractions 87 and 88 of cluster V (82-106) contained S100A8 (11 kDa), histone H4/H2B (12/15 kDa), lysozyme $\mathrm{C}(14 \mathrm{kDa})$, tropomyosin $\alpha-4(29 \mathrm{kDa})$, vimentin (55 kDa) and LTF ( $80 \mathrm{kDa}$ ), as shown with PMF (fig. 3; table 1).

The PMF data were further verified with immunoblotting using antibodies directed against HNP1-3, calprotectin, azurocidin, cathepsin $\mathrm{G}$, lysozyme $\mathrm{C}$ and LTF (data not shown). In addition, hCAP18 was identified in fractions 98-103 of cluster V with MALDI-MS and PMF. Furthermore, the mature peptide LL-37 could be detected in these fractions by Western blot analysis, utilizing a monoclonal antibody directed against LL-37 (data not shown).

Several hydrophobic components that eluted around $50 \%$ AcN (cluster VI, 117-120) were active against $S$. aureus, $H$. influenzae and moderately active against $M$. catarrhalis. Fraction 118 in cluster VI contained the calprotectin heterodimer S100A8/A9 $(10 / 13 \mathrm{kDa})$, hemoglobin subunit $\beta(14 \mathrm{kDa})$ and histone $\mathrm{H} 3(15 \mathrm{kDa})$, as determined by PMF (fig. 3; table 1). The most hydrophobic components (cluster VII, fractions 128-131) exhibited exclusive activity against $H$. influenzae and fractions 129- 


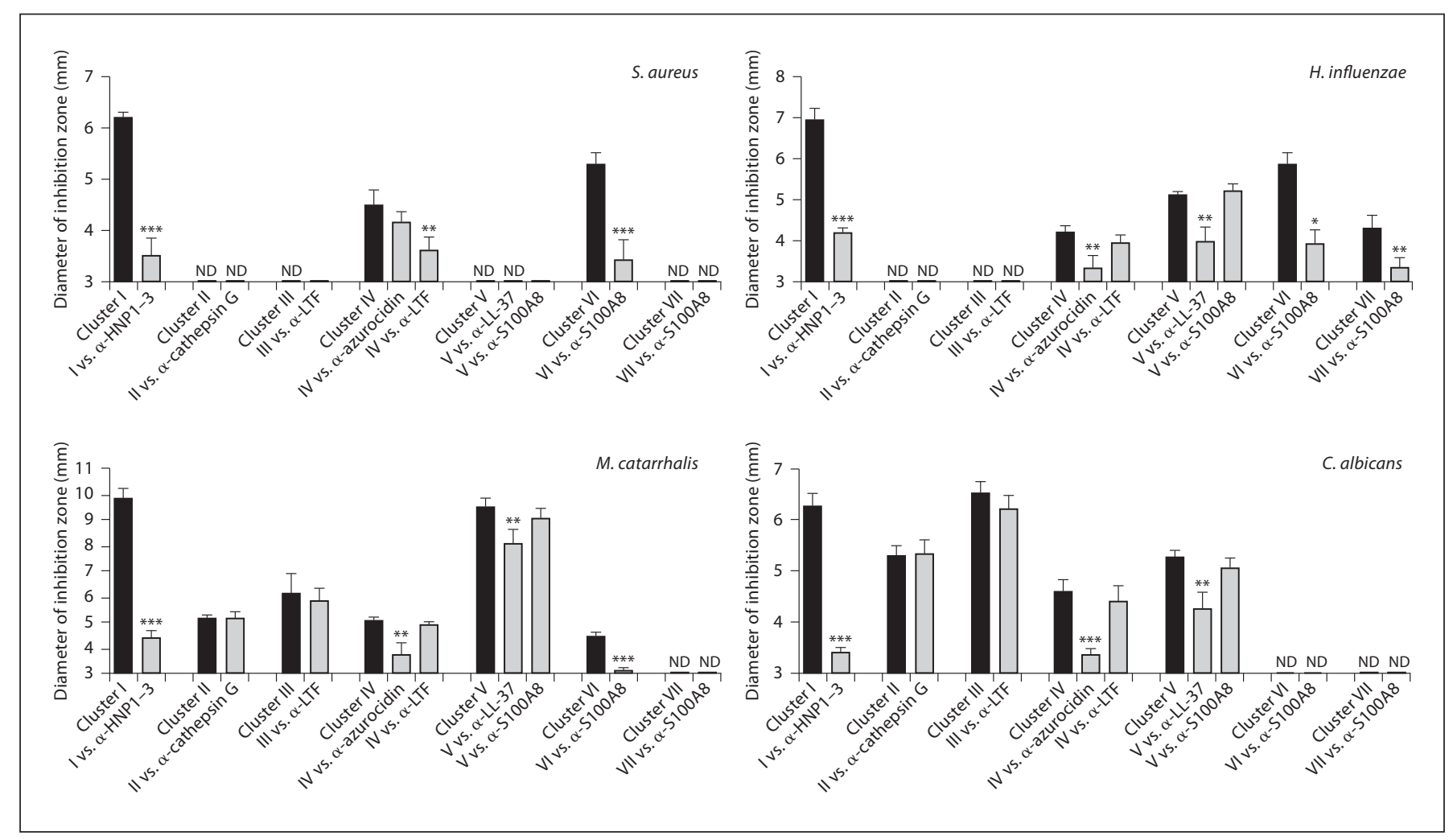

Fig. 4. Depletion of antimicrobial activity in pooled fractions from clusters I-VII. Antibodies directed against specific AMPs (marked as $\alpha$-AMP) identified in fractions displaying antimicrobial activity were incubated with pooled fractions (clusters I-VII) to examine if the antimicrobial activity could be abrogated (shown in grey bars). As controls (black bars) the pooled

fractions were incubated with unspecific antibody (mouse monoclonal anti-rabbit IgG). Not detected (ND) denotes where no antimicrobial activity was detected. Student's t test, unequal variances the depleted cluster (grey bar) compared to respective cluster control (black bar). $\mathrm{n}=4$ for each bar. ${ }^{*} \mathrm{p}<0.05$; ${ }^{* *} \mathrm{p}<$ $0.01 ;{ }^{* *} \mathrm{p}<0.005$.

131 were shown to contain calprotectin $(10 / 13 \mathrm{kDa})$, as shown by PMF (fig. 3; table 1).

\section{Depletion of Antimicrobial Activity from Specific \\ AMPs in Pooled Fractions}

Since most fractions contained several AMPs, it was necessary to determine the contribution of individual AMPs to the observed antimicrobial activity. Thus, depletion experiments with specific antibodies directed against individual antimicrobial polypeptides in clusters I-VII were carried through (fig. 4).

First, the specific antibodies were co-incubated with their respective synthetic peptide. This resulted in nearly full blocking of antimicrobial activity, demonstrating that the antibodies exhibited a blocking capacity (data not shown). When pooled fractions from cluster I were co-incubated with antibody against HNP1-3, a significant reduction in antimicrobial effect could be observed

for all strains. In contrast, no reduction in antimicrobial activity was detected upon incubation of cluster II with antibody against cathepsin G. Similarly, when fractions from cluster III were incubated with antibody directed against LTF, no significant reduction in antimicrobial activity against $M$. catarrhalis or $C$. albicans could be recorded.

When cluster IV was blocked with antibody against azurocidin, a significant reduction in antimicrobial activity against $H$. influenzae, $M$. catarrhalis and C. albicans was observed. Notably, when the same fractions were incubated with LTF antibody, the antimicrobial effect against $S$. aureus was attenuated, indicating speciesspecific effects of azurocidin and LTF.

For cluster $\mathrm{V}$ the antimicrobial activity directed against $H$. influenzae, $M$. catarrhalis and C. albicans was reduced after incubation with LL-37 antibody, whereas no reduction in activity was observed after application of 
Table 2. MIC of identified AMPs

\begin{tabular}{lllll}
\hline AMP & S. aureus & H. influenzae & M. catarrhalis & C. albicans \\
\hline LL-37 & 14.6 & 9.5 & 7.7 & 19.3 \\
HNP1-3 & 9.4 & 6.8 & 4.1 & 7.4 \\
S100A8/A9 & 2.74 & 2.7 & 3.05 & 3.6 \\
LTF & 1.69 & $>30$ & $>30$ & $>30$ \\
Lysozyme & $>300$ & $>300$ & $>300$ & 39 \\
Histones & $>15 \mathrm{mg} / \mathrm{ml}$ & $>15 \mathrm{mg} / \mathrm{ml}$ & $200 \mu \mathrm{g} / \mathrm{ml}$ & $26 \mu \mathrm{g} / \mathrm{ml}$ \\
\hline
\end{tabular}

MIC values of synthetic or purified AMPs were determined in an inhibition zone assay against $S$. aureus, $H$. influenzae, $M$. catarrhalis and C. albicans. MIC values are given in $\mu \mathrm{M}$, except where marked otherwise.

antibody against S100A8. A significant reduction in antimicrobial activity occurred when cluster VI was incubated with S100A8 antibody for all species, except for $C$. albicans. Finally, fractions in cluster VII were only active against $H$. influenzae and the antimicrobial effect was significantly reduced by co-incubation with the S100A8 antibody.

Combined, these experiments indicate that HNP1-3 and S100A8/A9 contribute to the antimicrobial activity against all species tested. The antimicrobial activity against $H$. influenzae, $M$. catarrhalis and $C$. albicans detected in cluster IV is exerted by azurocidin. However, azurocidin does not appear to play a major role in the detected activity against $S$. aureus. In contrast, LTF contributes to the observed antimicrobial effect directed against S. aureus in cluster IV, but not against the other pathogens investigated.

\section{Depletion of Antimicrobial Activity in PMN Extract}

Since most of the AMPs detected were found in several fractions with antimicrobial activity, we sought to evaluate the contribution of each AMP by depletion experiments of $\mathrm{PMN}$ extract utilizing antibodies against HNP1-3, azurocidin, lysozyme, cathepsin G, S100A8, LL-37 and LTF (fig. 5a). After incubation of the PMN extract with antibodies against HNP1-3, S100A8 or LTF, a significant reduction in antimicrobial activity against $S$. aureus was observed. In contrast, antibodies against azurocidin, lysozyme, cathepsin G or LL-37 did not significantly reduce the anti-staphylococcal activity of the PMN extract. For $H$. influenzae, depletion of the PMNextract with antibodies against HNP1-3, azurocidin or S100A8 resulted in a significant reduction in antimicrobial activity. A marked but not significant reduction was also observed in the PMN extract depleted with LL-37 antibody. No reduction in antimicrobial activity was detected utilizing antibodies directed against lysozyme, cathepsin G or LTF. The highest activity of the PMN extract was against $M$. catarrhalis and depletion experiments revealed that HNP1-3, azurocidin, S100A8 and LL-37 likely contributed to this activity.

In addition, the PMN extract had a potent anti-candida activity and similar depletion experiments indicated a role for HNP1-3 and S100A8 in the killing or inhibition of C. albicans (fig. 5a).

\section{PMN Extract Supplemented with Zinc and Iron}

Since we detected calprotectin and LTF in our screen, we wanted to determine the contribution of these and other metal-chelating AMPs to the activity of the PMN extract. Zinc has been shown to inhibit the bacteriostatic effects of calprotectin, present in large amounts in neutrophils. The exact mechanism behind this effect is not fully elucidated, but both zinc chelation [20] and other mechanisms have been proposed [21]. Further, ferrous iron abrogates the bacteriostatic effect of LTF $[20,22]$. We exploited these mechanisms to determine if any of the activity in the extract could be ascribed to calprotectin, LTF or other antimicrobial proteins that inhibit bacterial growth by a similar mechanism. PMN extract was dissolved in either water or $\mathrm{ZnSO}_{4}, \mathrm{FeSO}_{4}$ and $\mathrm{MgCl}_{2}$ solutions and the antimicrobial activity was measured. $\mathrm{ZnSO}_{4}$ reduced the antimicrobial activity with $35 \%$ for $S$. aureus, with $23 \%$ against $H$. influenzae, with $28 \%$ against $M$. catarrhalis and with $18 \%$ against $C$. albicans (fig. 5b). $\mathrm{FeSO}_{4}$ resulted in a similar reduction in activity but with a slightly less pronounced effect (fig. $5 \mathrm{~b}$ ). $\mathrm{MgCl}_{2}$ did not significantly alter the diameter of the inhibition zones for any of the species. Importantly, addition of ions did not alter the effect of a nonchelating AMP (LL-37), suggesting that the ions inactivated metal-chelating AMPs rather than inhibited the growth of the microorganism (fig. 5b).

\section{MIC of Individual AMPs}

To further establish a role in host defense for the identified AMPs and to corroborate the depletion experiments, MIC values of all 4 pathogens were determined by serial dilutions of each peptide in the inhibition zone assay (table 2). LL-37, HNP1-3 and calprotectin were found to inhibit growth of all 4 microorganisms. However, HNP1-3 and LL-37 exhibited slightly enhanced activity against $H$. influenzae and $M$. catarrhalis compared to $C$. albicans and S. aureus when tested in the inhibition zone 


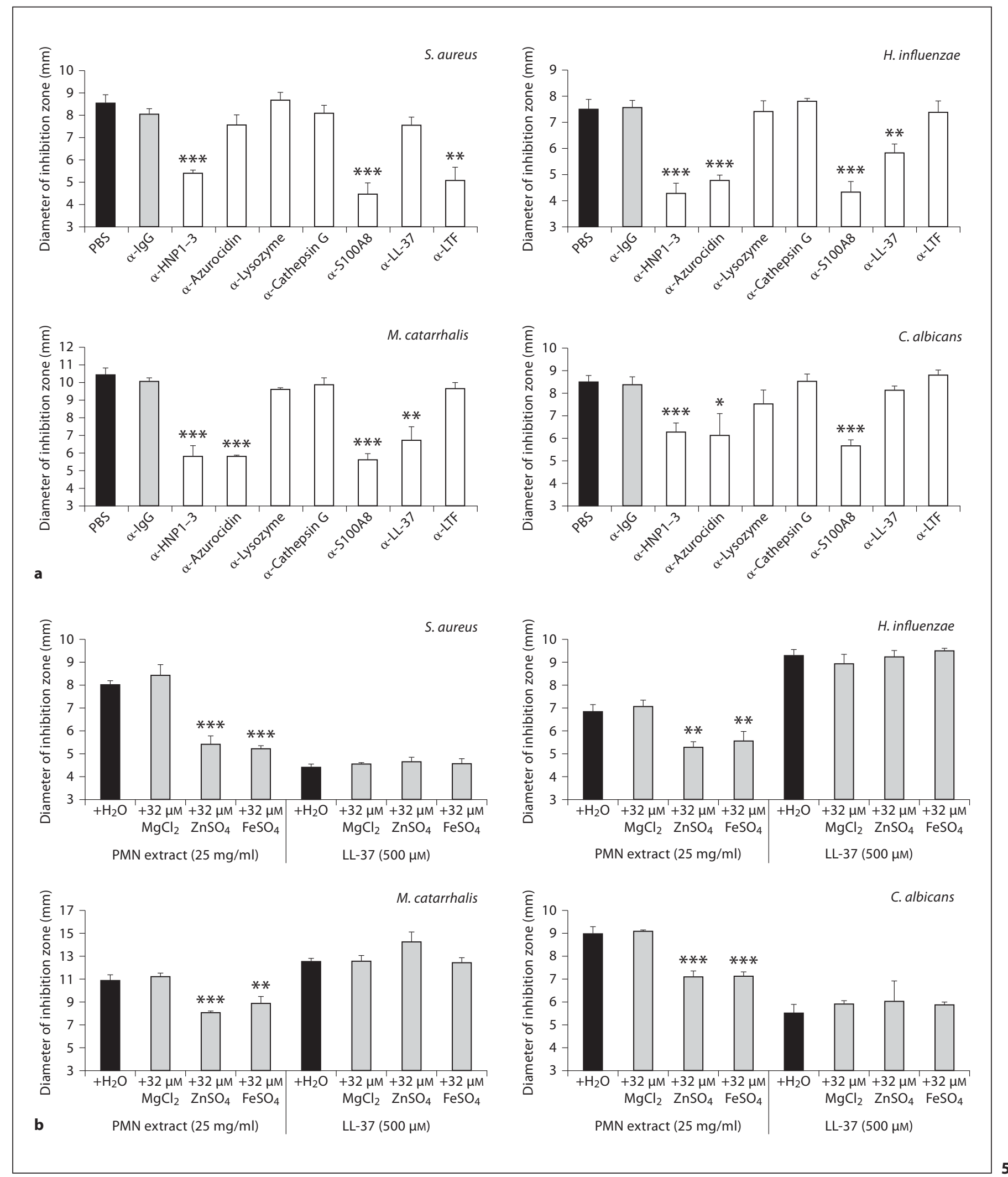

(For legend see next page.) 
assay. Calprotectin had the lowest MIC values for $S$. aureus and $H$. influenzae. Interestingly, LTF exhibited potent activity against $S$. aureus but was inactive at the highest concentrations assayed (MIC $>30 \mu \mathrm{M})$ against $H$. influenzae, M. catarrhalis and C. albicans. Lysozyme was only active against $C$. albicans, at quite high concentrations $(\mathrm{MIC}=39 \mu \mathrm{M})($ table 2$)$.

The presence of histones in several fractions with antimicrobial activity against $C$. albicans and $M$. catarrhalis and previous indications of antimicrobial activity of histones [23-25] led us to investigate the functional role of histones as antimicrobial proteins. Thus, histone sulfate (containing $\mathrm{H} 1, \mathrm{H} 2 \mathrm{~A}, \mathrm{H} 2 \mathrm{~B}, \mathrm{H} 3$ and $\mathrm{H} 4$ of bovine origin) was evaluated against the 4 test microbes. Interestingly, this mixture exhibited activity exclusively against $M$. catarrhalis and C. albicans, which suggests that histones contributed to the observed activity against these microbes in cluster II, III and V (fig. 2; table 2). Combined, the main findings of the antimicrobial activity against the selected microbes that originate from individual AMPs are summarized in figure 6 .

\section{Discussion}

Neutrophils contain numerous polypeptides with antimicrobial activity. Many of these have been thoroughly investigated in association with specific microbes. Here we extend previous findings with a novel screening approach with the aim to determine the specific 'set' of AMPs in neutrophils that is important in killing 4 human

Fig. 5. a Depletion of the antimicrobial activity of individual AMPs in PMN extract. Antibodies directed against individual AMPs (denoted as $\alpha$-AMP) identified in antimicrobial fractions were incubated with the PMN extract and antimicrobial activity measured (white bars). In parallel, depletion experiments using either PBS (black bars) or control antibody (mouse monoclonal anti-rabbit IgG) were carried out (marked $\alpha$-IgG, grey bars). The antimicrobial activity was assayed in the inhibition zone assay against $S$. aureus, $H$. influenzae, $M$. catarrhalis and $C$. albicans. Student's t test, unequal variances of depleted PMN extract compared to control $(\alpha-\operatorname{IgG}) . \mathrm{n}=3$ for each bar. ${ }^{*} \mathrm{p}<0.05 ;{ }^{* *} \mathrm{p}<0.01$; ${ }^{* * *} \mathrm{p}<0.005$. b Attenuation of antimicrobial activity of PMN extract by divalent metal ions. PMN extract and the antimicrobial peptide LL-37 was dissolved in either water (black bars), $32 \mu \mathrm{M}$ $\mathrm{ZnSO}_{4}, 32 \mu \mathrm{M} \mathrm{FeSO}_{4}$ or $32 \mu \mathrm{M} \mathrm{MgCl}_{2}$ (grey bars) and the antimicrobial activity was measured using the inhibition zone assay. Student's $t$ test, unequal variances of divalent metal metal ions compared to control $\left(\mathrm{H}_{2} \mathrm{O}\right.$ for either the PMN extract or LL-37). $\mathrm{n}=3$ for each bar. ${ }^{*} \mathrm{p}<0.05 ;^{* *} \mathrm{p}<0.01 ;{ }^{* * *} \mathrm{p}<0.005$. pathogens. Our hypothesis is that distinct sets of AMPs may have been evolutionarily adapted to interact with specific pathogens. Our current results support this idea and, indeed, we found that each pathogen is killed by several distinct AMPs with different mechanisms of action. A parallel attack using these AMPs exhibits a formidable threat to bacteria and an adaptation making them resistant to this combined assault is unlikely and would lead to a gross cost on bacterial fitness. Thus, the concept of attacking a microbe with multiple AMPs is perfectly exploited by neutrophils.

In the PMN extract we haveidentified 5 AMPs (HNP13, calprotectin, LTF, azurocidin and LL-37), which together appear to be responsible for a significant portion of the detected antimicrobial activity against the selected pathogens. In the depletion studies with specific antibodies and with MIC analyses for the individual AMPs, we encountered both specificity and redundancy in antimicrobial activity. The MIC values were in accordance with the depletion experiments, that is, if the activity of a polypeptide could be depleted, the MIC value for this polypeptide was low (calprotectin vs. S. aureus). Similarly, failure of depletion correlated with a high MIC value (LTF vs. H. influenzae). In addition, we identified hCAP18 (the precursor to LL-37) in our screen by using mass spectrometry with PMF. This precursor protein of $17 \mathrm{kDa}$ has no known antimicrobial activity per se. Nevertheless, we did observe a reduction in activity against $H$. influenzae, M. catarrhalis and C. albicans in the hCAP18-containing fractions, when depleting the activity with a monoclonal antibody against LL-37, which indicated the presence of active LL-37 in these fractions (fig. 4). Indeed, Western blot analysis of the PMN extract revealed that mature LL37 was present (fig. 1b). In addition, our MIC experiments suggest that LL-37 is active in vitro against $S$. aureus, which is in line with published data where MIC values for LL-37 against $S$. aureus strains varied between 2.9 and 2.5 $\mu \mathrm{M}$ [18]. However, the depletion experiments revealed that LL-37 appears to contribute very little to the total activity of the PMN extract against $S$. aureus (fig. 4, 5a). That both the holoprotein hCAP18 and LL-37 elute from the HPLC column in the same fraction has been observed before and suggests that they have a similar hydrophobicity index or that proteases cleave off LL-37 during the preparation [26].

We also identified lysozyme and cathepsin G, which are known antimicrobial polypeptides. However, antibodies directed against these proteins did not reduce the antimicrobial activity of the chromatographic fractions in which they were identified, indicating the presence of 
Fig. 6. Venn diagram summarizing the antimicrobial activity of the investigated AMPs. The combined results from the depletion experiments and MIC values reveal that LTF contributes to most of the activity against $S$. aureus, whereas lysozyme mainly exhibits activity against C. albicans. Histone seems to be one of the major AMPs responsible for killing both C. albicans and $M$. catarrhalis and azurocidin plays a major role in the antimicrobial activity against all pathogens assayed, except for S. aureus. Some AMPs also exhibit antimicrobial activities that are not limited to a specific microbial species, that is, calprotectin (S100A8/A9), HNP1-3 and LL37 have the capacity to kill all microbes assayed. However, the antimicrobial activity of LL-37 against $S$. aureus and C. albicans is less pronounced compared to $H$. influenzae and M. catarrhalis.

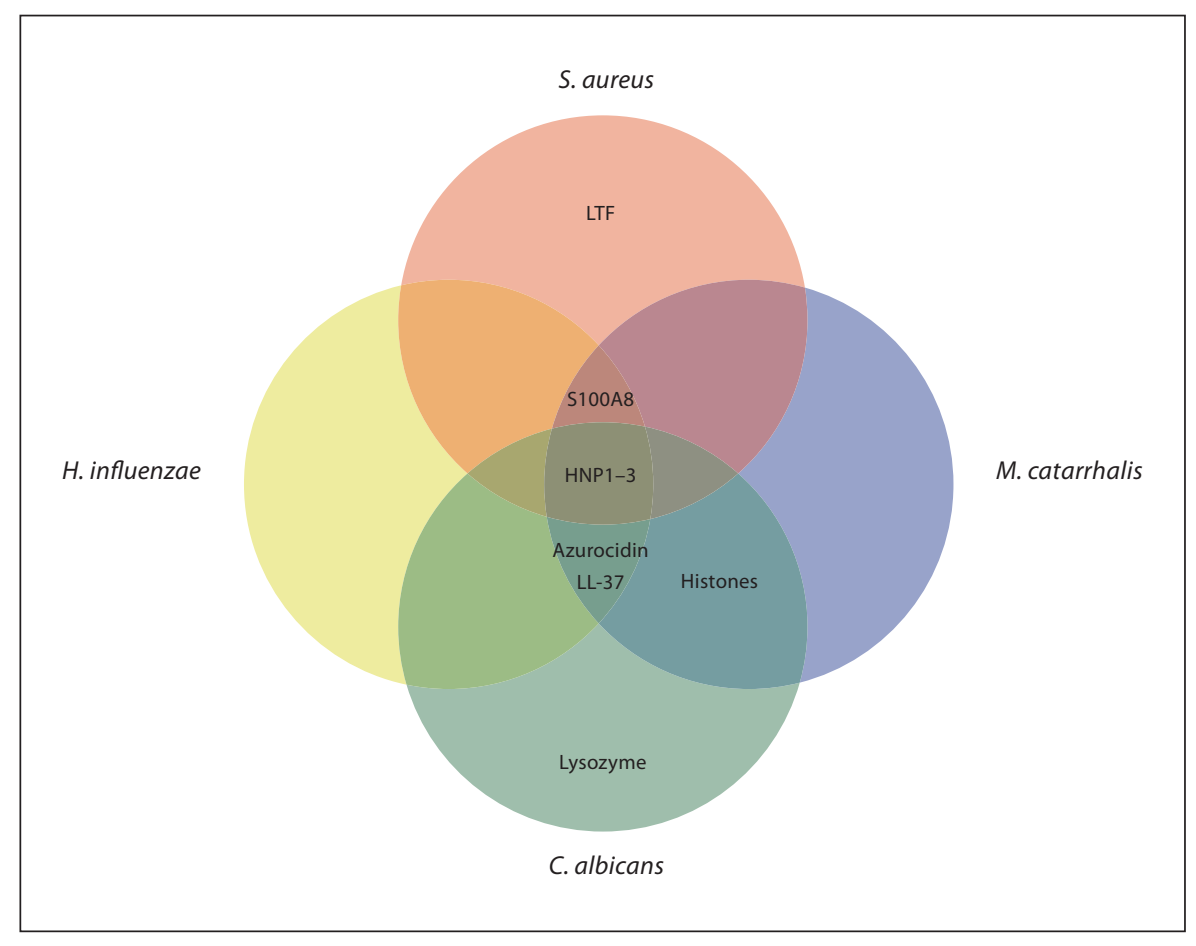

unidentified or untested AMPs in these fractions. Since we used a harsh extraction procedure (1\% TFA in $60 \%$ acetonitrile), the antimicrobial activity of enzymatic AMPs such as cathepsin G may have been disrupted through denaturation. This may explain why fractions containing antimicrobial enzymes did not exhibit antimicrobial activity in the inhibition zone assay. Therefore, this limitation of our screen infers that we cannot rule out a role for cathepsin G, lysozyme or other enzymatic AMPs in neutrophil-derived killing of the 4 selected pathogens. However, purified lysozyme was not very effective in killing any of the tested microbes in our MIC analysis (table 2), which is consistent with previous findings that clinical isolates are resistant against this AMP as part of their virulence [27]. Importantly, the extraction procedure did not interfere with the activity of cationic and metal-binding AMPs, since identified defensins, hCAP18/LL-37, azurocidin, calprotectin as well as LTF were active in our screen. In addition, we identified histones in several fractions with activity against $M$. catarrhalis and C. albicans (fig. 2, clusters II, III and V; tables 1,2$)$. The contribution of histones to this activity was supported by our MIC assay on histone sulfate, which exhibited activity predominantly against $M$. catarrhalis and C. albicans (table 2). Thus, our results support previous work on histones [25] and are in line with the emerging concept that histones function as true AMPs [23]. In fact, several histones have been found in NETs, where they contribute to bacterial and fungal killing together with other AMPs [28, 29].

To include both nuclear, cytoplasmic as well as granular neutrophil-derived proteins in our antimicrobial screen, whole neutrophils were lysed and enriched for peptides and proteins. Thus, our extraction procedure yielded neutrophil-derived polypeptides from both membrane-bound and intracellular compartments, including all subsets of neutrophil granules. Indeed, we have found both $\alpha$-defensins $1-3$ and azurocidin from primary granules, LTF, LL-37 and NGAL from the specific granules as well as cofilin 1 and vimentin from gelatinase granules [30]. Further, we identified the cytosolic calprotectin heterodimer (S100A8/A9) as an important AMP in neutrophils. Calprotectin (also called calgranulin) resides in the cytosol and is the most abundant protein in human neutrophils, constituting approximately $45 \%$ of the total protein content in these cells [31]. It has been demonstrated that calprotectin plays an important role in growth inhibition of $C$. albicans by necrotic neutrophils [32] as well as by NETs [28].

The MIC values that we obtained were in the same range as previously published MIC values for these AMPs versus the respective microbe $[18,20,21,33-35]$. How- 
ever, MIC values of AMPs should be compared with caution since conditions differ significantly between laboratories and there is currently no consensus in this methodology. We investigated several different conditions and chose the method which could be used for all peptides and microbes. Moreover, metal-chelating AMPs such as calprotectin and LTF had to be analyzed in a medium low in divalent cations, in order to avoid saturation of the binding sites for these ions that would block the bacteriostatic mechanism of action. This may have influenced the growth of the organism and thus the resulting MIC values. Another factor that influences the MIC value is the bacterial strain used. Here we have used clinical isolates, which may be relevant for future studies into this area, where biological samples from patients are investigated.

Combined, our experiments reveal that neutrophils kill bacteria by using a wide range of AMPs, utilizing different mechanisms of action for killing or growth restriction. This represents an example of redundancy that has often been suggested, but not proven, concerning the role of AMPs in host defense. The fact that several AMPs kill bacteria simultaneously, and by different mechanisms, minimizes the risk of bacterial resistance. On the other hand, AMPs exhibit a specific action to many bacteria. This phenomenon may explain why the composition of the normal flora varies between different body sites. The skin releases psoriasin, an S100 protein inhibiting bacterial growth by chelating $\mathrm{Zn}^{2+}$, which readily kill Escherichia coli, but is inactive against $S$. aureus [36]. Recently, Salzman et al. [37] showed that mice expressing human defensin 5 have an altered composition of the normal flora compared to wild-type mice. Thus, the emerging concept is that AMPs contribute to the shaping of the normal flora at mucosal surfaces. Therefore, it is important to delineate the precise role of each AMP against individual bacterial species.

However, an important limitation with our approach is that we study individual components separately. Thus, we do not discover synergistic activity between the different AMPs, suggesting that we probably underestimate the total effect of AMPs in the neutrophil antimicrobial repertoire.

In addition to exploring the role of AMPs in relation to the normal flora, there are ongoing attempts to induce AMPs as a strategy to treat infections [38]. Our results point out a role for HNP1-3 and calprotectin against all pathogens investigated, while LL-37, LTF and azurocidin exhibited a narrower spectrum. Interestingly, recent data show that LL-37, calprotectin and azurocidin are expressed in bronchial epithelial cells and are induced by
IL-17 and IL-22 $[39,40]$. These cytokines are released from a newly described $T$ helper cell subset, the $T_{h} 17$ cells, which have been suggested to be master regulators of mucosal defense. Notably, cytokines released from $\mathrm{T}_{\mathrm{h}} 17$ cells also recruit neutrophils to the site of infection. Thus, the final outcome of $T_{h} 17$ cell activation at the site of infection is a rapid increase in AMP levels, which originate both from epithelial cells and PMNs [41]. Notably, several recent reports describe conditions where deficient $\mathrm{T}_{\mathrm{h}} 17$ cell responses are implicated in susceptibility to severe $S$. aureus and C. albicans infections [42-44]. We speculate that these conditions may also result in a deficiency of specific AMPs and we believe that our present results on neutrophil-derived AMPs may be useful for future studies on clinical entities involving susceptibility to bacterial and fungal infections.

\section{Acknowledgements}

This work was supported by the Swedish Foundation for Strategic Research, the Swedish Research Council (58X-11217-14-3), the Torsten and Ragnar Söderberg Foundation, the Swedish Cancer Society and Karolinska Institutet. P.B. is supported by grants from Magnus Bergwall's and Åke Wiberg's Foundations as well as by The David and Astrid Hagelén Foundation.

The authors thank Prof. Hans Jörnvall for editorial assistance. Min Wan for supplying isolated neutrophils, Dr. Martin Vondracek for sequencing M. catarrhalis and H. influenzae isolates, Prof. Lennart Lindbom for supplying azurocidin, Dr. Eva-Lena Ericsson for kind gifts of the clinical isolates of M. catarrhalis and $H$. influenzae and Dr. Walter J. Chazin for providing recombinant calprotectin.

References sis and the resolution of infection. Immunol Res 2009;43:25-61.

$\checkmark 2$ Craig A, Mai J, Cai S, Jeyaseelan S: Neutrophil recruitment to the lungs during bacterial pneumonia. Infection and Immunity 2009;77:568-575.

-3 Schwartzberg LS: Neutropenia: etiology and pathogenesis. Clin Cornerstone 2006; 8(suppl 5):S5-S11.

4 Zeidler C, Boxer L, Dale DC, Freedman MH, Kinsey S, et al: Management of Kostmann syndrome in the G-CSF era. Br J Haematol 2000;109:490-495.

5 Carlsson G, Andersson M, Putsep K, Garwicz D, Nordenskjold M, et al: Kostmann syndrome or infantile genetic agranulocytosis, part one: celebrating 50 years of clinical and basic research on severe congenital neutropenia. Acta Paediatr 2006;95:15261532. 
6 6 Putsep K, Carlsson G, Boman HG, Andersson M: Deficiency of antibacterial peptides in patients with morbus Kostmann: an observation study. Lancet 2002;360:1144-1149.

$\checkmark 7$ Ganz T, Metcalf JA, Gallin JI, Boxer LA, Lehrer RI: Microbicidal/cytotoxic proteins of neutrophils are deficient in two disorders: Chediak-Higashi syndrome and 'specific' granule deficiency. J Clin Invest 1988;82: 552-556.

8 Ganz T: Defensins: antimicrobial peptides of innate immunity. Nat Rev Immunol 2003;3: 710-720.

-9 Agerberth B, Gudmundsson GH: Host antimicrobial defence peptides in human disease. Curr Top Microbiol Immunol 2006; 306:67-90.

-10 Campanelli D, Detmers PA, Nathan CF, Gabay JE: Azurocidin and a homologous serine protease from neutrophils. Differential antimicrobial and proteolytic properties. J Clin Invest 1990;85:904-915.

-11 Steinbakk M, Naess-Andresen CF, Lingaas E, Dale I, Brandtzaeg P, et al: Antimicrobial actions of calcium binding leucocyte L1 protein, calprotectin. Lancet 1990;336:763-765.

-12 Houghton AM, Hartzell WO, Robbins CS, Gomis-Ruth FX, Shapiro SD: Macrophage elastase kills bacteria within murine macrophages. Nature 2009;460:637-641

$\checkmark 13$ de Haar SF, Hiemstra PS, van Steenbergen MT, Everts V, Beertsen W: Role of polymorphonuclear leukocyte-derived serine proteinases in defense against Actinobacillus actinomycetemcomitans. Infect Immun 2006; 74:5284-5291.

-14 Di Gennaro A, Kenne E, Wan M, Soehnlein $\mathrm{O}$, Lindbom L, et al: Leukotriene B4-induced changes in vascular permeability are mediated by neutrophil release of heparinbinding protein (HBP/CAP37/azurocidin). FASEB J 2009;23:1750-1757.

$\checkmark 15$ Bradford MM: A rapid and sensitive method for the quantitation of microgram quantities of protein utilizing the principle of proteindye binding. Anal Biochem 1976;72:248254

-16 Lehrer RI, Rosenman M, Harwig SS, Jackson $\mathrm{R}$, Eisenhauer P: Ultrasensitive assays for endogenous antimicrobial polypeptides. J Immunol Methods 1991;137:167-173.

-17 Yoshio H, Tollin M, Gudmundsson GH, Lagercrantz $\mathrm{H}$, Jornvall $\mathrm{H}$, et al: Antimicrobial polypeptides of human vernix caseosa and amniotic fluid: implications for newborn innate defense. Pediatr Res 2003;53:211-216.

-18 Turner J, Cho Y, Dinh NN, Waring AJ, Lehrer RI: Activities of LL-37, a cathelin-associated antimicrobial peptide of human neutrophils. Antimicrob Agents Chemother 1998; 42:2206-2214.
19 Sorensen O, Arnljots K, Cowland JB, Bainton DF, Borregaard N: The human antibacterial cathelicidin, hCAP-18, is synthesized in myelocytes and metamyelocytes and localized to specific granules in neutrophils. Blood 1997;90:2796-2803.

20 Corbin BD, Seeley EH, Raab A, Feldmann J, Miller MR, et al: Metal chelation and inhibition of bacterial growth in tissue abscesses. Science 2008;319:962-965.

21 Murthy AR, Lehrer RI, Harwig SS, Miyasaki $\mathrm{KT}$ : In vitro candidastatic properties of the human neutrophil calprotectin complex. J Immunol 1993;151:6291-6301.

22 Arnold RR, Russell JE, Champion WJ, Brewer M, Gauthier JJ: Bactericidal activity of human lactoferrin: differentiation from the stasis of iron deprivation. Infect Immun 1982; 35:792-799.

23 Kai-Larsen Y, Bergsson G, Gudmundsson GH, Printz G, Jornvall H, et al: Antimicrobial components of the neonatal gut affected upon colonization. Pediatr Res 2007;61:530 536.

24 Lee DY, Huang CM, Nakatsuji T, Thiboutot $\mathrm{D}$, Kang SA, et al: Histone $\mathrm{H} 4$ is a major component of the antimicrobial action of human sebocytes. J Invest Dermatol 2009;129:2489_ 2496.

25 Hirsch JG: Bactericidal action of histone. Exp Med 1958;108:925-944.

26 Bals R, Wang X, Zasloff M, Wilson JM: The peptide antibiotic LL-37/hCAP-18 is expressed in epithelia of the human lung where it has broad antimicrobial activity at the airway surface. Proc Natl Acad Sci USA 1998; 95:9541-9546

27 Davis KM, Akinbi HT, Standish AJ, Weiser JN: Resistance to mucosal lysozyme compensates for the fitness deficit of peptidoglycan modifications by Streptococcus pneumoniae. PLoS Pathog 2008;4:e1000241.

28 Urban CF, Ermert D, Schmid M, Abu-Abed U, Goosmann C, et al: Neutrophil extracellular traps contain calprotectin, a cytosolic protein complex involved in host defense against Candida albicans. PLoS Pathog 2009; 5:e1000639.

29 von Kockritz-Blickwede M, Nizet V: Innate immunity turned inside-out: antimicrobial defense by phagocyte extracellular traps. J Mol Med 2009;87:775-783.

30 Lominadze G, Powell DW, Luerman GC Link AJ, Ward RA, et al: Proteomic analysis of human neutrophil granules. Mol Cell Proteomics 2005;4:1503-1521.

31 Edgeworth J, Gorman M, Bennett R, Freemont P, Hogg N: Identification of p8,14 as a highly abundant heterodimeric calcium binding protein complex of myeloid cells. J Biol Chem 1991;266:7706-7713.
32 McNamara MP, Wiessner JH, Collins-Lech C, Hahn BL, Sohnle PG: Neutrophil death as a defence mechanism against Candida albicans infections. Lancet 1988;2:1163-1165.

$\checkmark 33$ Aguila A, Herrera AG, Morrison D, Cosgrove $\mathrm{B}$, Perojo $\mathrm{A}$, et al: Bacteriostatic activity of human lactoferrin against Staphylococcus aureus is a function of its iron-binding properties and is not influenced by antibiotic resistance. FEMS Immunol Med Microbiol 2001;31:145-152.

-34 Lusitani D, Malawista SE, Montgomery RR: Calprotectin, an abundant cytosolic protein from human polymorphonuclear leukocytes, inhibits the growth of Borrelia burgdorferi. Infect Immun 2003;71:4711-4716.

35 Clarke SR, Foster SJ: Isd A protects Staphylococcus aureus against the bactericidal protease activity of apolactoferrin. Infect Immun 2008;76:1518-1526.

36 Glaser R, Harder J, Lange H, Bartels J, Christophers E, et al: Antimicrobial psoriasin (S100A7) protects human skin from Escherichia coli infection. Nat Immunol 2005;6: 57-64.

37 Salzman NH, Hung K, Haribhai D, Chu H, Karlsson-Sjoberg J, et al: Enteric defensins are essential regulators of intestinal microbial ecology. Nat Immunol 2010;11:76-83.

- 38 Raqib R, Sarker P, Bergman P, Ara G, Lindh $\mathrm{M}$, et al: Improved outcome in shigellosis associated with butyrate induction of an endogenous peptide antibiotic. Proc Natl Acad Sci USA 2006;103:9178-9183.

39 Aujla SJ, Chan YR, Zheng M, Fei M, Askew DJ, et al: IL-22 mediates mucosal host defense against Gram-negative bacterial pneumonia. Nat Med 2008;14:275-281.

40 Nograles KE ZL, Guttman-Yassky E, Fuentes-Duculan J, et al: Th17 cytokines interleukin (IL)-17 and IL-22 modulate distinct inflammatory and keratinocyte-response pathways. Br J Dermatol 2008;159:10921102.

41 Kolls JK, McCray PB Jr, Chan YR: Cytokinemediated regulation of antimicrobial proteins. Nat Rev Immunol 2008;8:829-835.

42 Ferwerda B, Ferwerda G, Plantinga TS, Willment JA, van Spriel AB, et al: Human dectin-1 deficiency and mucocutaneous fungal infections. N Engl J Med 2009;361:17601767.

43 Glocker EO, Hennigs A, Nabavi M, Schaffer AA, Woellner C, et al: A homozygous CARD9 mutation in a family with susceptibility to fungal infections. N Engl J Med 2009;361:1727-1735.

44 Milner JD, Brenchley JM, Laurence A, Freeman AF, Hill BJ, et al: Impaired $\mathrm{T}(\mathrm{H}) 17$ cell differentiation in subjects with autosomal dominant hyper-IgE syndrome. Nature 2008;452:773-776. 